\title{
Experimental study on rock-breaking mechanism of micro-coring PDC bit
}

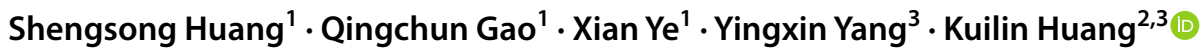

Received: 26 August 2021 / Accepted: 6 December 2021 / Published online: 13 December 2021

(c) The Author(s) 2021

\begin{abstract}
In this paper, in order to study the rock-breaking mechanism of the micro-coring PDC bit, a series of unit breaking experiments containing 2 breaking forms (static-pressure breaking and fracture breaking) are conducted on core columns of sandstone, limestone, and granite. Besides, a full-sized micro-coring PDC bit with a diameter of $152.4 \mathrm{~mm}$ is designed and manufactured and is used to conduct an indoor experiment on multiple sized sandstone core columns. The unit breaking experiment results show that ROP (rate of penetration) of the fracture breaking is higher than the static-pressure breaking. The indoor experiment results of the full-sized bit show that ROP of the micro-coring PDC bit is 49-112\% higher than the conventional bit and that the diameter of core column shows greater influence on ROP, while the height of the column shows smaller. Moreover, the micro-coring PDC bit realizes volumetric fracture on all of the three types of rock samples. Since volumetric fracture produces large rock debris, the rock-breaking efficiency and ROP of the micro-coring PDC bit will be improved significantly.
\end{abstract}

Keywords Micro-coring $\cdot$ PDC bit $\cdot$ Rock-breaking mechanism $\cdot$ Experimental study $\cdot$ Rock-breaking efficiency

\section{Introduction}

The PDC bit, adopting polycrystalline diamond compacts (PDC) as cutting elements, is of good performance (high ROP, long service life, and low drilling cost) in oil and gas drilling operation when drilling in soft, medium, and hard formations. To verify the geological conditions in oil and gas exploration, rock sampling is required to determine the lithology and the mineral component in the formation. Nevertheless, the debris generated by the conventional PDC bits is in powder form which is too small for formation identification, thus, bits of different functions (drilling and coring) must be changed to meet the requirements of both drilling and coring(Xin 2015; Jing et al. 2014).

Kuilin Huang

huangklin@126.com

1 Great Wall Drilling Company

of China National Petroleum Corporation, Panjin 124000, China

2 School of Control Engineering, Chengdu University of Information Technology, Chengdu 610225, China

3 School of Mechanical Engineering, Southwest Petroleum University, Chengdu 610500, China
In view of the above conditions, a series of researches has been carried around the world, among which a mechanical micro-coring PDC bits is put forward (as shown in Fig. 1) (Wang Tian Yu 2017; Huichao et al. 2016). This kind of micro-coring PDC bit (hereinafter referred to as the microcoring bit) can push the fractured core column outwardly by utilizing the physical force of the rock itself. Compared with the conventional PDC bit, the micro-coring bit has its own structure characteristics. In the micro-coring bit, cutters are no longer set at the central area of the bit, but a central groove instead. And there is a rock-fracturing structure at the bottom or the side of the groove, which could be a slanted plane, a PDC cutter, or a conical tooth. The central area of the micro-coring bit does not have the ability of rock-breaking, so that a piece of rock column (i.e., the core column) will be formed in corresponding area in the bottom hole. When the column grows up to a certain height, it will step in the central groove of the bit and engages the rockfracturing structure, then it will be fractured by the axial or lateral force from the fracturing structure. After that, the core column, as well as other rock debris, will be removed by the drilling fluid along the flow channel on the bit. On the other hand, a suction micro-coring bit is put forward by Kuang Yuchun (Yuchun et al. 2017). Being designed with a 

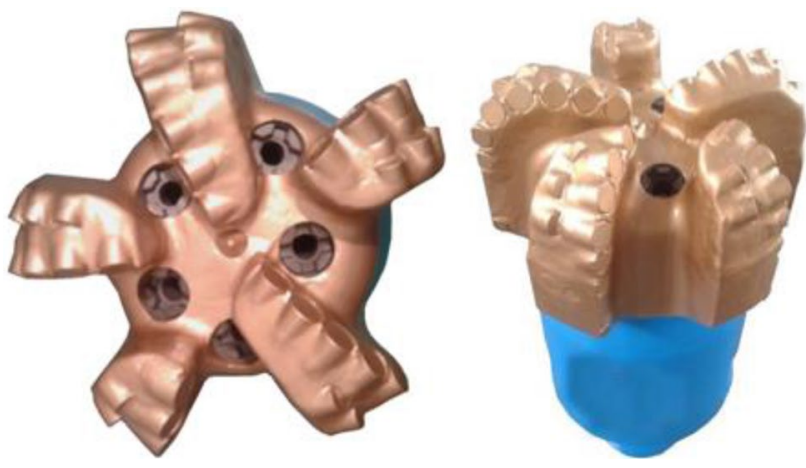

Fig.1 Micro-coring PDC bit

specific hydraulic structure (arranging a coring channel and a jet flow channel), the bit is able to remove the fractured core columns along the flow channel with suction force. Onsite application shows that both of the two micro-coring bits mentioned above can increase the ROP to a certain extent.

In order to study the rock-breaking mechanism of the micro-coring PDC bit, a series of unit breaking experiments and indoor experiment on the full-sized micro-coring PDC bit are conducted to analyze the breaking regularity of core columns in different sizes, and the experiment results are used to select the most suitable core column type and the most efficient rock-breaking method, so as to provide theoretical support for the optimization of micro-coring PDC bit and to increase the drilling speed in different formations.

\section{Unit breaking experiment}

There are mainly two methods for the micro-coring bits to break the core column: static-pressure breaking and fracture breaking. Energy consumptions of different breaking methods are quite different, and the sizes of rock debris generated by different methods are different as well. On the other hand, the sizes (diameter and height) of the core column have direct influences on the rock-breaking efficiency, even for the same sized core column, the breaking sensitivities are not the same when using different breaking methods. Therefore, unit breaking experiments of static-pressure breaking and fracture breaking are, respectively, carried out on three types of core columns (sandstone, limestone, and granite), and all the rock samples (i.e., the core columns) are prepared with different sizes.

\section{Static-pressure breaking experiment}

\section{Experimental equipment and rock samples}

The experimental equipment for static-pressure breaking including a hydraulic tester, a displacement sensor, a pressure sensor, CZ1319 conical tooth (with tooth holder), and a DAQ system (i.e., the data acquisition system), as shown in Fig. 2. The conical tooth is fixed on the pressure sensor through the tooth holder, and the pressure sensor is further mounted on the hydraulic tester. The application of hydraulic load is realized by the up movement of the tester, and the signals from displacement sensor and pressure sensor are transferred to the computer for data acquisition through a strain gauge.

The rock samples (partly shown in Fig. 3) for staticpressure breaking experiment are divided into three groups and each group includes all three types of rock samples. In the first group, the diameters of different types are $20 \mathrm{~mm}$, being the same, while the heights are, respectively, $20 \mathrm{~mm}$, $25 \mathrm{~mm}, 30 \mathrm{~mm}, 35 \mathrm{~mm}$, and $40 \mathrm{~mm}$. In the second group, the heights of different types are $30 \mathrm{~mm}$, being the same, while the diameters are, respectively, $20 \mathrm{~mm}, 25 \mathrm{~mm}$, $30 \mathrm{~mm}, 35 \mathrm{~mm}$, and $40 \mathrm{~mm}$. Some of core column samples are shown in Fig. 3. As for the third group, the rock samples are cuboids with the sizes of $300 \mathrm{~mm} \times 100 \mathrm{~mm} \times 100 \mathrm{~mm}$.

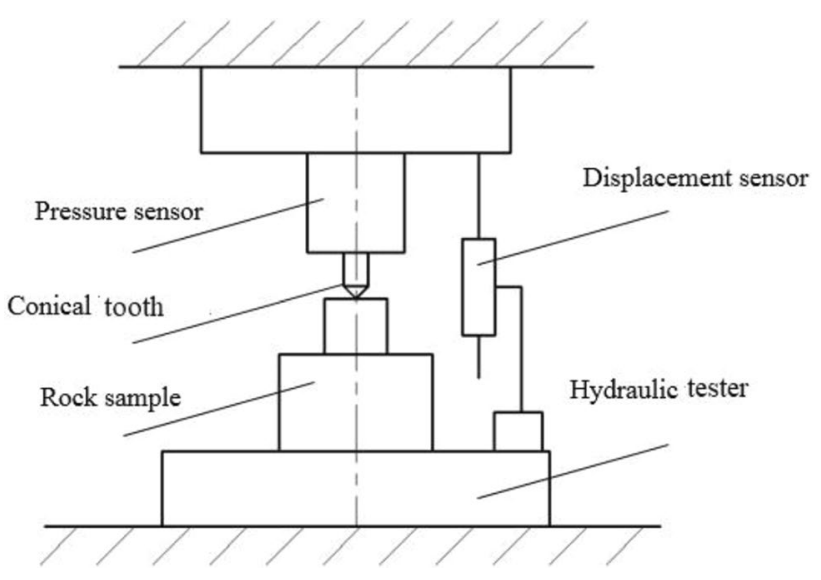

Fig.2 Schematic diagram of the experimental equipment for staticpressure breaking

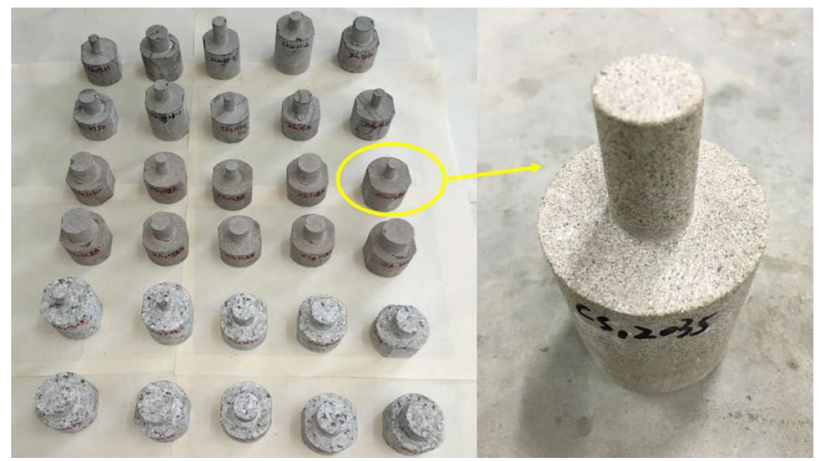

Fig. 3 Different core column rock samples 
Table 1 Lithology parameters of the three types of rock samples

\begin{tabular}{lllllll}
\hline Rock samples & $\begin{array}{l}\text { Uniaxial compres- } \\
\text { sive strength /MPa }\end{array}$ & $\begin{array}{l}\text { Shear } \\
\text { strength / } \\
\mathrm{MPa}\end{array}$ & $\begin{array}{l}\text { Internal fric- } \\
\text { tion angle }{ }^{\circ}\end{array}$ & $\begin{array}{l}\text { Elastic } \\
\text { Modulus/ } \\
\text { GPa }\end{array}$ & Poisson's ratio & Density \\
\hline Sandstone & 67.548 & 13.56 & 38.03 & 11.54 & 0.062 & 2.42 \\
Limestone & 105.951 & 17.72 & 43.62 & 31.2 & 0.171 & 2.46 \\
Granite & 126.519 & 13.7 & 45.29 & 31.78 & 0.118 & 2.73 \\
\hline
\end{tabular}

Fig. 4 Experiment process of the static-pressure breaking

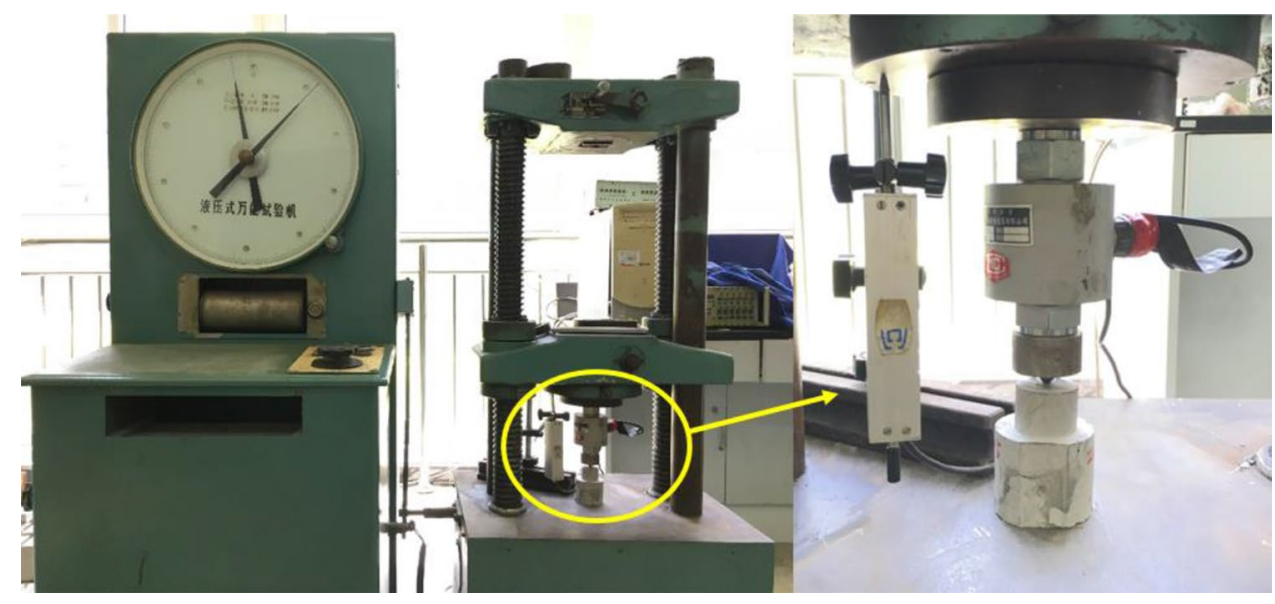

For all three types of rock samples, the lithology parameters are listed in Table1.

\section{The principle and method of the experiment}

The tested rock sample is placed in the center of the tester's platform. Further, the horizontal position of the rock sample is adjusted so that its cylinder axis is aligned with the cusp of the conical tooth, and the height of the test platform is adjusted so that the tooth cusp is about $1 \mathrm{~mm}$ above the rock sample. Meanwhile, the DAQ system is cleared and the sampling process is started. Then pressure load will be gradually exerted on the rock sample (as shown in Fig. 4) until the sample is broken, and then, the pressure will be unloaded. During the whole process, the experimental data are recorded and displayed by the DAQ system, and the broken rock debris is collected and properly stored. This is a whole process of one unit experiment, and each experiment is repeated for at least 3 times.

\section{Fracture breaking experiment}

\section{Experimental equipment and rock samples}

The experimental equipment for fracture breaking includes a hydraulic tester, a displacement sensor, a pressure sensor, 1308 PDC cutter (with cutter holder), and a DAQ system, as shown in Fig. 5.

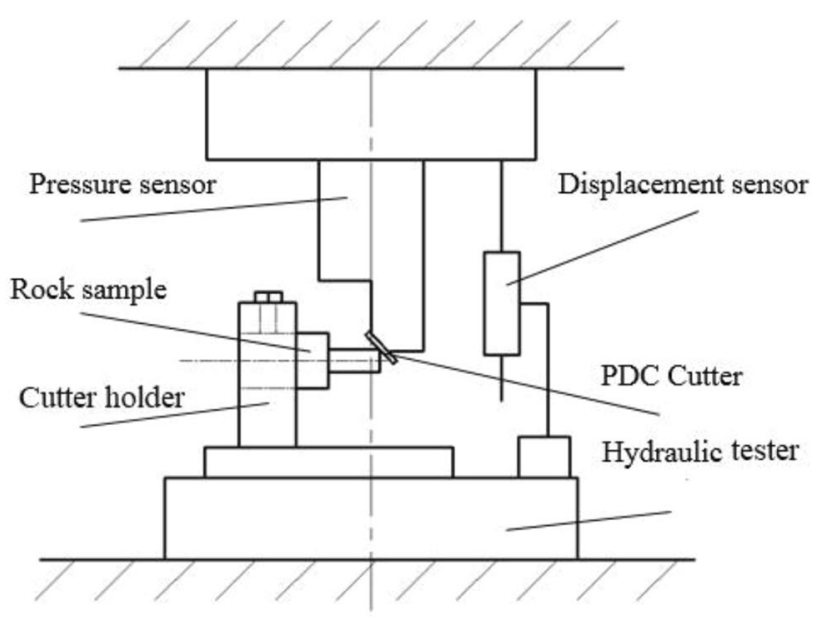

Fig. 5 Schematic diagram of the experimental equipment for fracture breaking

The rock samples (partly shown in Fig. 3) for fracture breaking experiment are divided into two groups and each group includes all three types of rock samples. In the first group, the diameters of different types are $20 \mathrm{~mm}$, being the same, while the heights are, respectively, $20 \mathrm{~mm}, 25 \mathrm{~mm}$, $30 \mathrm{~mm}, 35 \mathrm{~mm}, 40 \mathrm{~mm}, 45 \mathrm{~mm}$, and $50 \mathrm{~mm}$. In the second group, the heights of different types are $25 \mathrm{~mm}$, being the same, while the diameters are, respectively, $15 \mathrm{~mm}, 20 \mathrm{~mm}$, $25 \mathrm{~mm}, 30 \mathrm{~mm}, 35 \mathrm{~mm}$, and $40 \mathrm{~mm}$. 


\section{The principle and method of the experiment}

Similar as the static-pressure breaking experiment, the tested rock sample in the fracture experiment is also placed in the center of the tester's platform. By adjusting the position of the rock fixture, the axes of the rock sample and the cutter holder are set in the same plane and perpendicular to each other. Further, the height of the test platform is adjusted so that the cutter face just contact with the rock sample. Meanwhile, the DAQ system is cleared and the sampling process is started. Then pressure load will be gradually exerted on the rock sample (as shown in Fig. 6) until the sample is broken, and then the pressure will be unloaded. During the whole process, the experimental data are recorded and displayed by the DAQ system, and the broken rock debris is collected and properly stored. Each experiment is repeated for at least 3 times.

\section{Evaluation criteria for rock-breaking efficiency of single tooth}

Due to different evaluation indexes, there are many evaluation criteria for rock-breaking efficiency of single tooth/cutter. As a result, proper criteria should be chosen according to different rock-breaking mechanisms. Below are two often used evaluation criteria for rock-breaking efficiency(Deschamps et al. 2008; INC 2016).

\section{(1) Specific volumetric breaking work}

First, the rock-breaking work is defined as follow:

$W=\int_{0}^{h_{\max }} f(h) d h$

where $W$ is the work applied by a single tooth during its one rock-breaking process (from start contacting the rock to finish breaking the rock) and $f(h)$ is the function of the exerted load $F$ with respect to the depth $h$ (penetration depth of the tooth). Both $W$ and $h$ are derived from the load-displacement curve.

Take $A_{V}$ as the specific volumetric breaking work (hereinafter referred to as specific work) and $V$ as the volume of the broken rock removed by the tooth, then $A_{V}$ should be represented as:

$A_{V}=\frac{W}{V}$

For rock-breaking efficiency of single tooth, $A_{V}$ is one of the often used evaluation criteria. It is concluded that the smaller the $A_{V}$, the higher the rock-breaking efficiency and vice versa. The specific volumetric breaking work is an effective criteria for quantitative evaluation of rockbreaking efficiency.

\section{(2) Rock debris granularity}

Rittinger's surface theory (Technologies and L.P 2015; Meng et al. 2016; Chengdu Best Diamond Bit Co Ltd 2013) suggests that the physical and mechanical properties of rock have not changed before and after rock-breaking, only the fragmentation degree (represented by the surface area) of the rock has changed. The new surface theory suggests that most of the work applied for breaking the rock is used to form the new surface. Take the original fragmentation degree of the rock as $D$, which becomes $d$ after breaking. The surface area of a unit volume rock is in direct proportion to the value of $\frac{1}{d}-\frac{1}{D}$. Thus, the specific work should be:

$A v=K r\left(\frac{1}{d}-\frac{1}{D}\right)$

where $K_{r}$ is a constant related to breaking methods and mechanical properties of rock.
Fig. 6 Experiment process of the fracture breaking

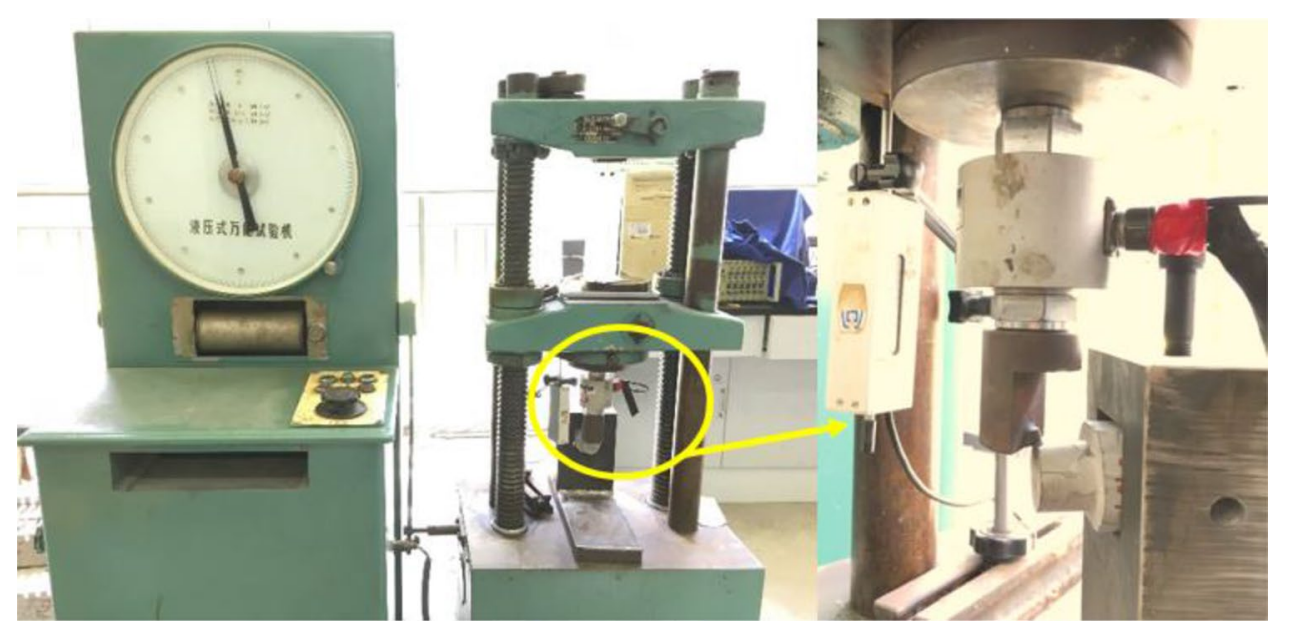


Generally, the average granularity is used to represent the fragmentation degree of rock, which is defined as:

$d e=\frac{\sum(\text { ridi })}{\sum r i}$

where $d_{i}$ is the size of a certain granularity, and $\gamma_{i}$ is the percentage of the granularity.

If the rock sample is large enough and the size of rock debris (generated in rock-breaking process) is small enough, then $\frac{1}{D}$ is far less than $\frac{1}{d}$, then Eq. (3) can be simplified as:

$A v=K r \frac{1}{d}$

Equation (5) shows that the breaking work ratio is inversely proportional to the granularity of rock debris, namely the larger the size of rock debris, the smaller the specific work, and the higher the rock-breaking efficiency.

\section{Results and analysis of the unit breaking experiment}

\section{Results and analysis of static-pressure breaking}

In the static-pressure breaking experiment, some tiny debris is first generated below the tooth, as the pressure load increases, tiny debris gradually becomes compacted rock core. As carrier and transmitter of the mechanical energy, the compacted core acts as a wedge pushed into the rock. With the increase of loading, the tensile stress between the core and the ambient rock becomes larger, when it exceeds the tensile strength of the rock, cracks around the core will be extended to the rock surface along the direction of maximum tensile stress, thus breaking the rock. On the one hand, when penetrating in a flat rock surface, internal stress of the rock will counteract some of the tensile stress (in the load direction) and will prevent cracks from extending to the deep. As a result, only cracks in the shallow area can be extended, and when the cracks are extended to free surface of the rock, rock material in the shallow area will be broken and removed (Fig. 7). On the other hand, since there are no constraints around the core column, the counteraction effect of the internal stress is relatively weak, cracks are able to extend to the root of the core column and then break the column when they reach the free surface (Fig. 8). Compared with the flat rock samples (Fig. 7), rock debris generated from the core column is bigger (Fig. 9). In other words, the core column generates larger rock-breaking volume and requires lower energy consumption than the flat rock.

As an important index to measure the breaking efficiency of the tooth, the specific works of different flat rocks and core columns are, respectively, calculated and compared. As shown in Fig. 10 and Fig. 11, the specific work of the flat sandstone is $112.5 \mathrm{~J} / \mathrm{cm} 3$, while the maximum specific work of sandstone core column is $0.6 \mathrm{~J} / \mathrm{cm}^{3}$, being only $0.5 \%$ of the flat rock. For limestone, the specific work of the flat rock is $90.1 \mathrm{~J} / \mathrm{cm} 3$, while the maximum of core column is
Fig. 7 Breaking pits and debris of the flat rocks in staticpressure breaking: a-sandstone; b-limestone; c-granite
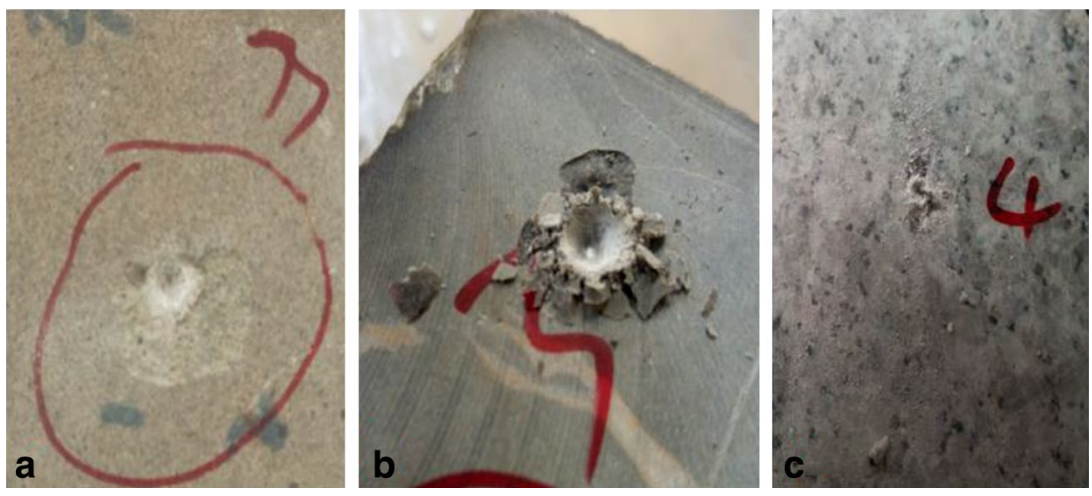

Fig. 8 Broken core columns in static-pressure breaking: a-sandstone; b-limestone; c-granite
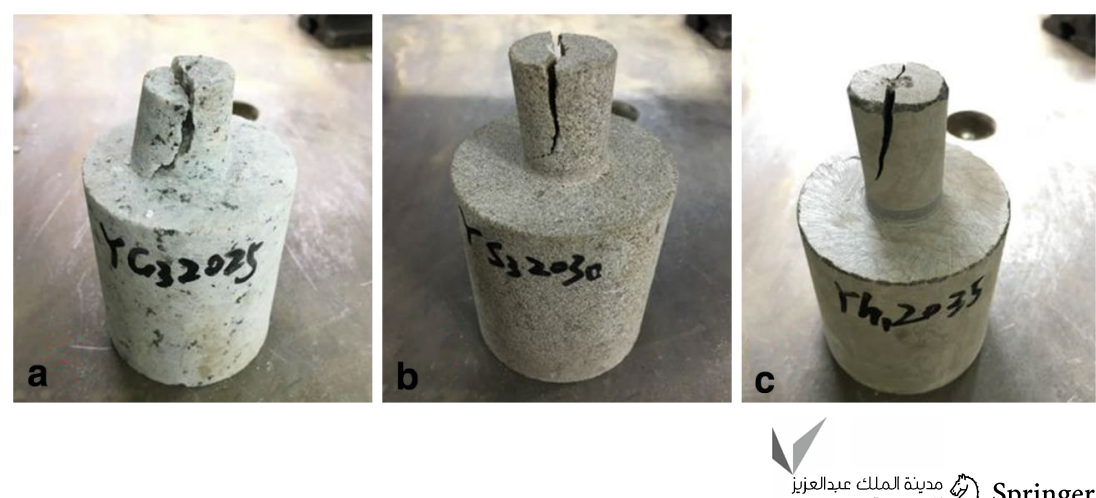

كدينة الملك عبدالعزي 
Fig. 9 Debris of core columns in static-pressure breaking: a-sandstone; b-limestone; c-granite

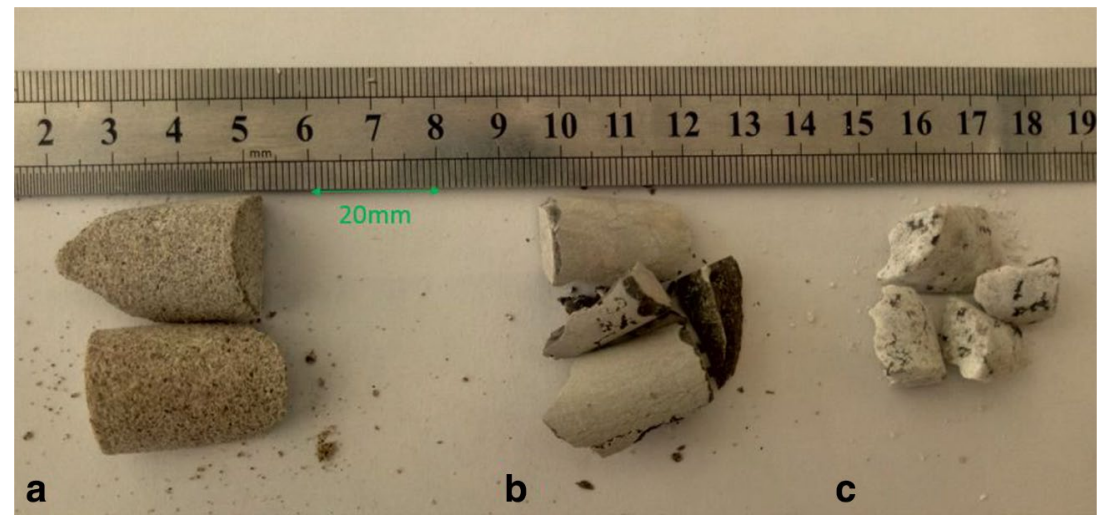

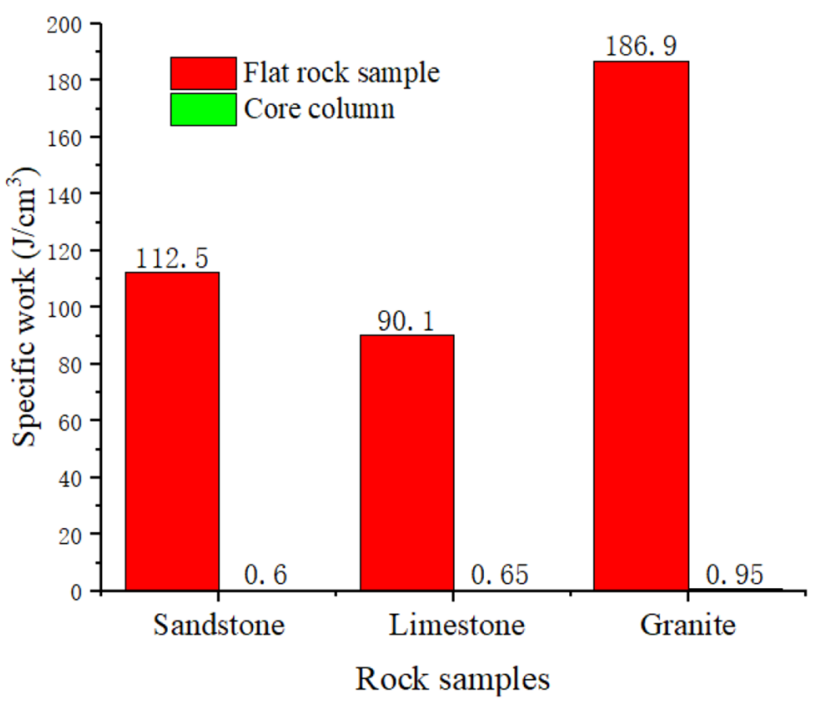

Fig. 10 Specific work of flat rocks s and core columns in static-pressure breaking

$0.65 \mathrm{~J} / \mathrm{cm}^{3}$, being only $0.7 \%$ of the flat rock. For granite, the specific work of the flat rock is $186.9 \mathrm{~J} / \mathrm{cm} 3$, while the maximum of core column is $0.95 \mathrm{~J} / \mathrm{cm}^{3}$, being only $0.51 \%$ of the flat rock. It can be concluded that the specific work of core column is much smaller than that of the flat rock, besides, the breaking sensitivities of three rock types to the shapes of rock samples are different, sandstone is the most sensitive, followed by granite and limestone.

As shown in Fig. 11a, for core columns of the same height and with a diameter of $20 \mathrm{~mm}$, the specific work of granite is higher than that of sandstone and limestone. As the heights increase, the specific works of granite and sandstone do not change obviously, but for that of limestone, there is a slight fluctuation. Specifically, granite, sandstone, and limestone have got their minimum specific works when the column heights are, respectively, $35 \mathrm{~mm}, 35 \mathrm{~mm}$, and $30 \mathrm{~mm}$. As shown in Fig. 11b, as the diameter increases, the specific work of sandstone does not change obviously, but for that of limestone and granite, there are some fluctuations. Specifically, granite, sandstone, and limestone have got their minimum specific works when the column diameters are, respectively, $20 \mathrm{~mm}, 35 \mathrm{~mm}$, and $30 \mathrm{~mm}$.

\section{Results and analysis of fracture breaking}

When the PDC cutter contacts the core column, a concentrated compressive stress will be generated in the contacting area, causing a brittle fracture there, some tiny debris will drop from the column. Meanwhile, the concentrated force at the top of the column produces a bending moment in the root of the column, resulting in a bending deformation of the column. As a result, one side of the column will be tensed (by tensile stress) while the other be compressed
Fig. 11 Specific work variation in static-pressure experiment
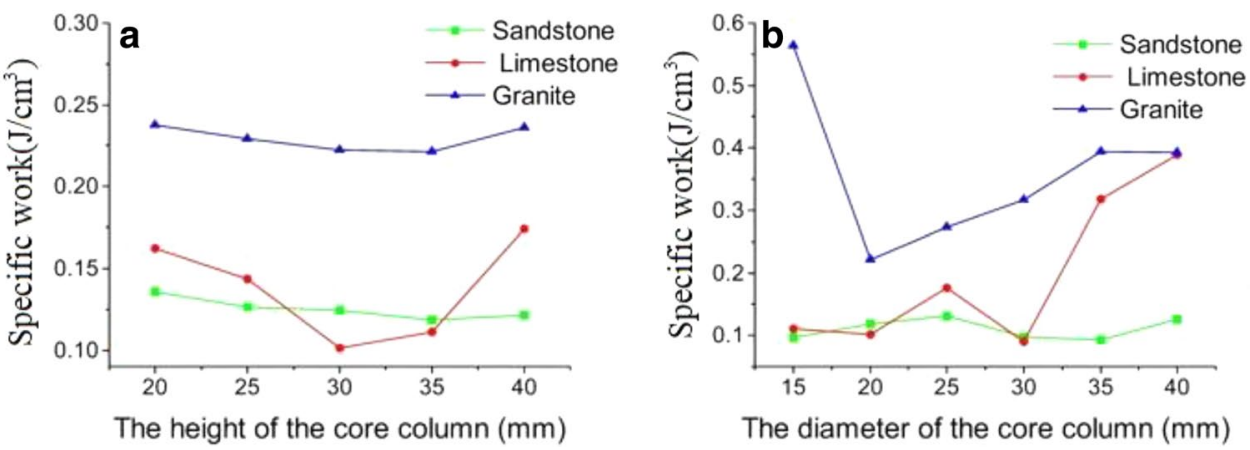
Fig. 12 Broken core columns in fracture breaking: a-sandstone; b-limestone; c-granite
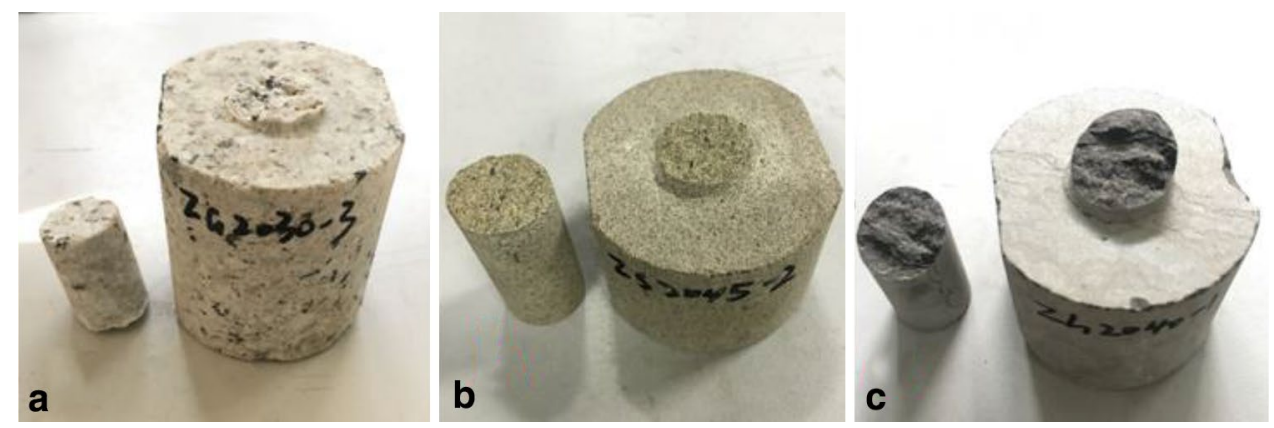

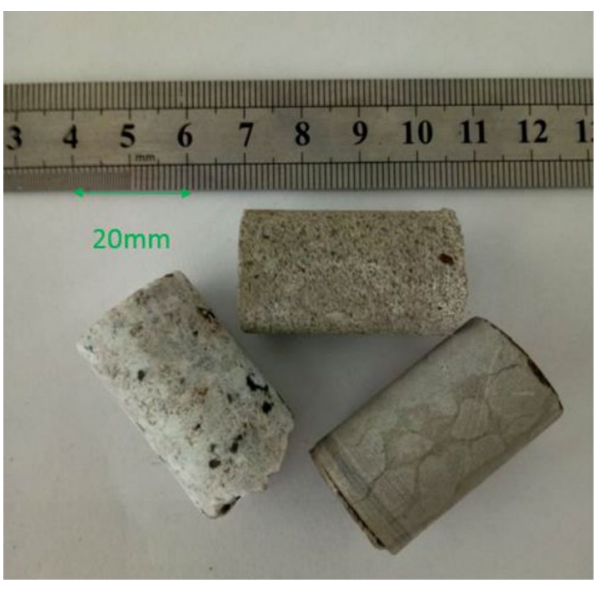

Fig. 13 Fractured fragments in fracture breaking

(by compressive stress), and the tension side of the column will be stretched while the compression side will be shortened. As shown in Fig. 12, once the tensile stress exceeds the tension strength of rock sample, cracks will appear on the tension side and will further stretch to the compression side, till the core column is broken. As shown in Fig. 13, the fractured rock from the core columns are not tiny chippings, but relatively complete cylinders. Nevertheless, when the heights of sandstone, limestone, and granite are greater than $45 \mathrm{~mm}, 40 \mathrm{~mm}$, and $30 \mathrm{~mm}$, respectively, due to different lithology and the defects in rock samples, the core columns are not likely to be fractured at the roots of the columns, but in the middle instead.

The specific works of different core columns are, respectively, shown in Fig. 14. When the core columns are of the same height, the specific work of the limestone is the highest, as shown in Fig. 14a. Besides, specific works of all three kinds of rock decrease obviously with the increase of heights. Specifically, specific works of sandstone and granite tend to be constant when the height approaches $35 \mathrm{~mm}$, specific work of limestone remains constant when the height approaches $40 \mathrm{~mm}$. When the height is around $50 \mathrm{~mm}$, specific works of all rock samples reach the minimum. On the other hand, with the increase of diameter, specific work of limestone increases stepwise, while specific works of the sandstone and granite appear to decrease slightly before increasing, as shown in Fig. 14b. For limestone, the specific work gets its minimum when the diameter is $15 \mathrm{~mm}$, while for sandstone and granite, both the minimum points are around $20 \mathrm{~mm}$.

\section{Analysis on the unit breaking experiment}

It can be concluded from unit breaking experiment that the core column generated by the micro-coring bit realizes volumetric breaking of the rock, and specific work consumed by the core column is far less than that consumed by the flat rock, which indicates that the existence of proper sized core column can improve the rock-breaking efficiency of the bit, whether the micro-coring bit is applied in in soft, medium,
Fig. 14 Specific works of core columns of different sizes in fracture breaking
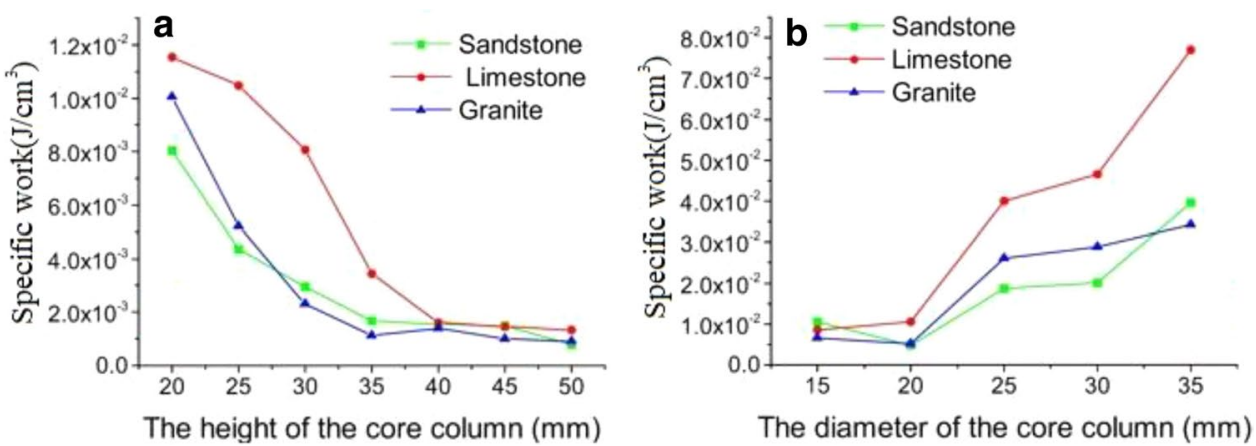

The diameter of the core column $(\mathrm{mm})$ 
or hard formation. On the other hand, by contrasting the rock fragments collected in unit breaking experiment, as shown in Fig. 9 and Fig. 13, it can be found that the fragment size in the fracture breaking is much larger than that in static-pressure breaking, indicating that the rock-breaking efficiency of fracture is much higher than that of static pressure.

\section{Indoor experiment on micro-coring PDC bit}

In the unit breaking experiment, it is found that the existence of core column is beneficial to rock-breaking of the bit and that size of the column has great influence on rockbreaking efficiency. Nevertheless, core columns of different sizes in the unit experiment are not generated in actual drilling, but prefabricated. Considering that the actual drilling is a complex process affected by many factors (WOB, TOB, and RPM), prefabricated core columns may not reveal the actual performance of the micro-coring bit, so that a fullsized micro-coring bit of $\varphi 152.4 \mathrm{~mm}$ is designed and manufactured as a test bit. For the test bit, both the diameter and height of the core column are adjustable, specifically, the diameter can be adjusted in the range of $0-30 \mathrm{~mm}$, and the height can be chosen at $20 \mathrm{~mm}, 30 \mathrm{~mm}$, or $40 \mathrm{~mm}$.

\section{Design and manufacture of micro-coring bit}

The crown profile of the test bit is relatively a flat curve which comprises a shallow inner-cone, a single arc and a short outer-cone. On the other hand, the bit is designed with five wing blades considering its cutter density, and the cutter arrangement is designed in accordance with equal cuttingvolume principle. Compared with common PDC bit, the test bit has a radial adjusting blade and a replaceable central rock-fracturing module. The diameter of the core column can be adjusted by the radial slip of the adjusting blade, while the height of the core column can be adjusted by changing the central rock-fracturing module. As illustrated in Fig. 15, after manufacturing of bit body, the adjusting blade and the central rock-fracturing module as well as welding of the PDC cutters, all the parts of the test bit are assembled.

\section{Experiment on the micro-coring test bit}

\section{Experimental instruments and rock samples}

The instruments of the experiment include a test rack, sensor joints, and a DAQ system. The data including WOB, TOB, and displacement are collected from the sensors and then transferred to the computer through a strain gauge for data acquisition. The rock sample in this experiment is a sandstone cube with the sizes of $300 \mathrm{~mm} \times 300 \mathrm{~mm} \times 300 \mathrm{~mm}$.

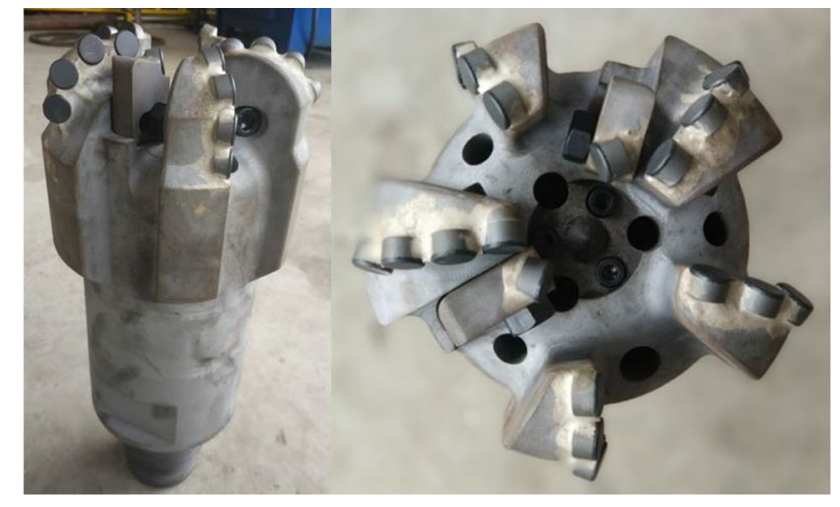

Fig. 15 The micro-coring PDC test bit

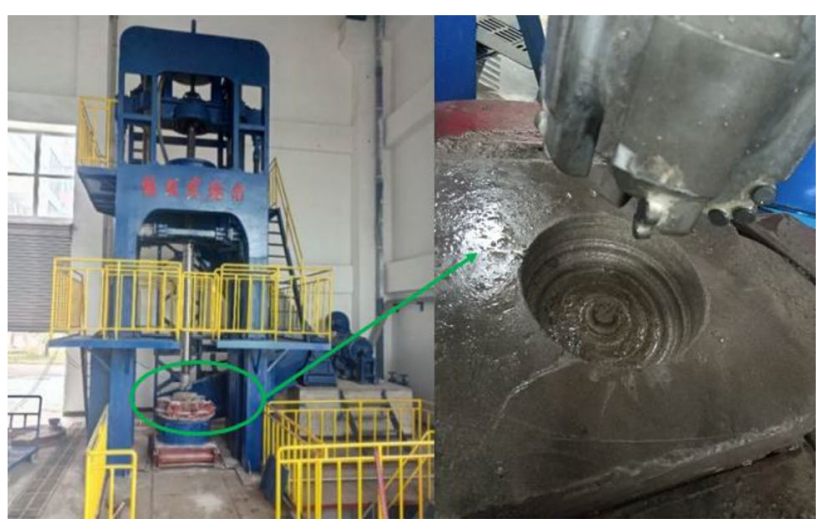

Fig. 16 Drilling process of the test bit

\section{The principle and method of the experiment}

The properly adjusted test bit is connected to a drill rod and the sandstone sample is fixed on a rotary table. The rotating speed of the rotary table is set at $10 \mathrm{r} / \mathrm{min}$, and the WOB is adjusted in the range of $10 \sim 15 \mathrm{kN}$. Before starting the experiment, the bit is slowly lowered and penetrates in the rotating rock sample to build an initial bottom hole. When the experiment is started, the speed of the rotary table and WOB will be adjusted at the set value, and then the DAQ system will be reset and stated to collect experimental data. After reaching the predetermined drilling depth, the drilling process will be stopped and the rock debris will be collected. The drilling process of the test bit is shown in Fig. 16. Each group of the experiment is repeated for at least 3 times.

\section{Experiment results and analysis}

When the diameter or height of the core column is 0 , the test bit becomes a full-covering bit, of which the bottom hole, as shown in Fig. 17a, is a series of concentric-circle tracks scraped by PDC cutters. For a full-covering bit, 

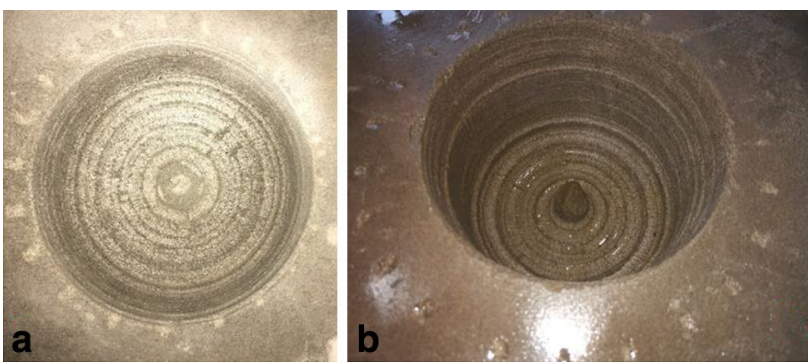

Fig. 17 Bottom holes of the bits: a-full-covering bit; b-micro-coring bit

rock-breaking of the bit depends entirely on the scraping or cutting of PDC cutters, and the size of rock debris (mostly below $10 \mathrm{~mm}$, as shown in Fig. 18a) is obviously smaller than that of a non-full-covering bit. As for the bottom hole of the micro-coring bit, except the concentric-circle tracks

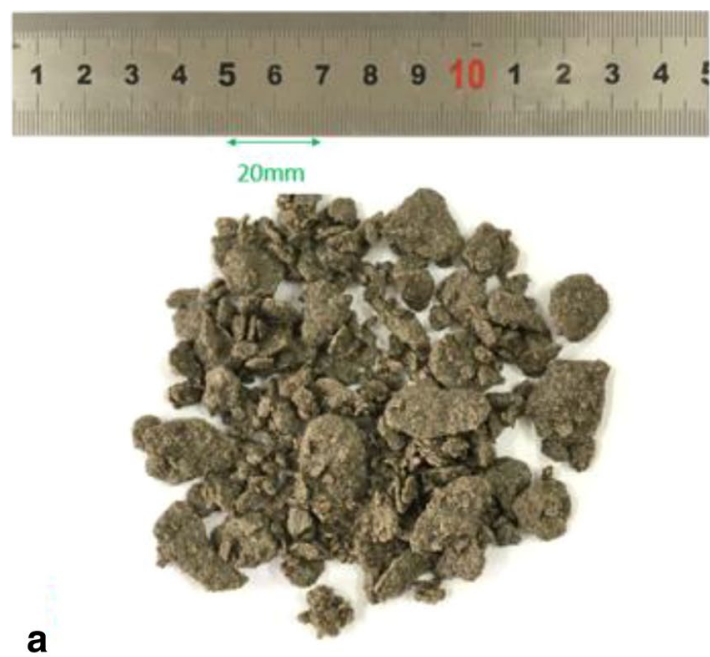

Fig. 18 Rock debris of the bits: a-full-covering bit; b-micro-coring bit

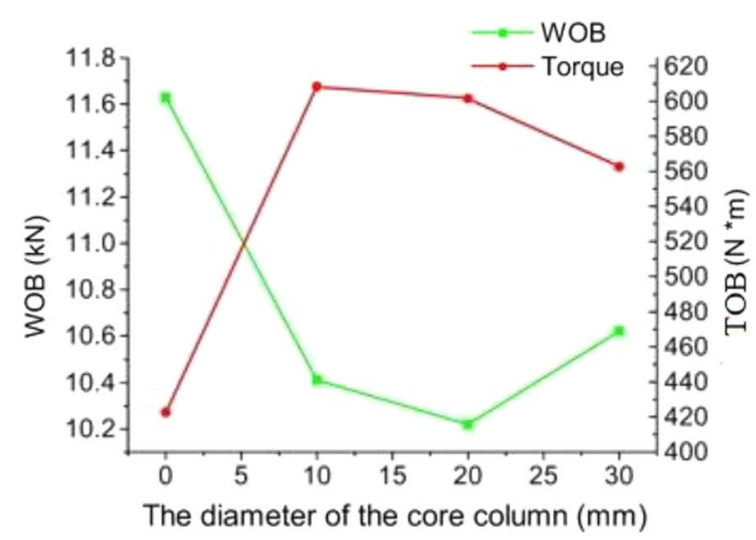

formed by PDC cutters, a fractured core column can be found in the center of the bottom hole, as shown in Fig. 17b. Compared with common full-covering bit, larger rock debris (mostly larger than $20 \mathrm{~mm}$, as shown in Fig. 18b) is obtained in the micro-coring bit experiment, and most of the debris is in mass form.

The variations of WOB and TOB with the diameter and height of the core column are shown in Fig. 19. It can be found that the WOB fluctuates between 10 and $12 \mathrm{kN}$. For the full-covering situation (when diameter or height of the column is zero), the maximum reaches $11.63 \mathrm{kN}$ when all cutters penetrate in the rock, and that the minimum TOB is about $422.4 \mathrm{Nm}$ and while minimum ROP is $0.33 \mathrm{~m} / \mathrm{h}$. In the experiment of changing the diameter of core column, TOB of the micro-coring bit (when both the diameter and height of the column are not zero) substantially decreases with the increase of diameter. As shown in Fig. 20, ROP of the micro-coring bit decreases with the increase of the

\section{b}
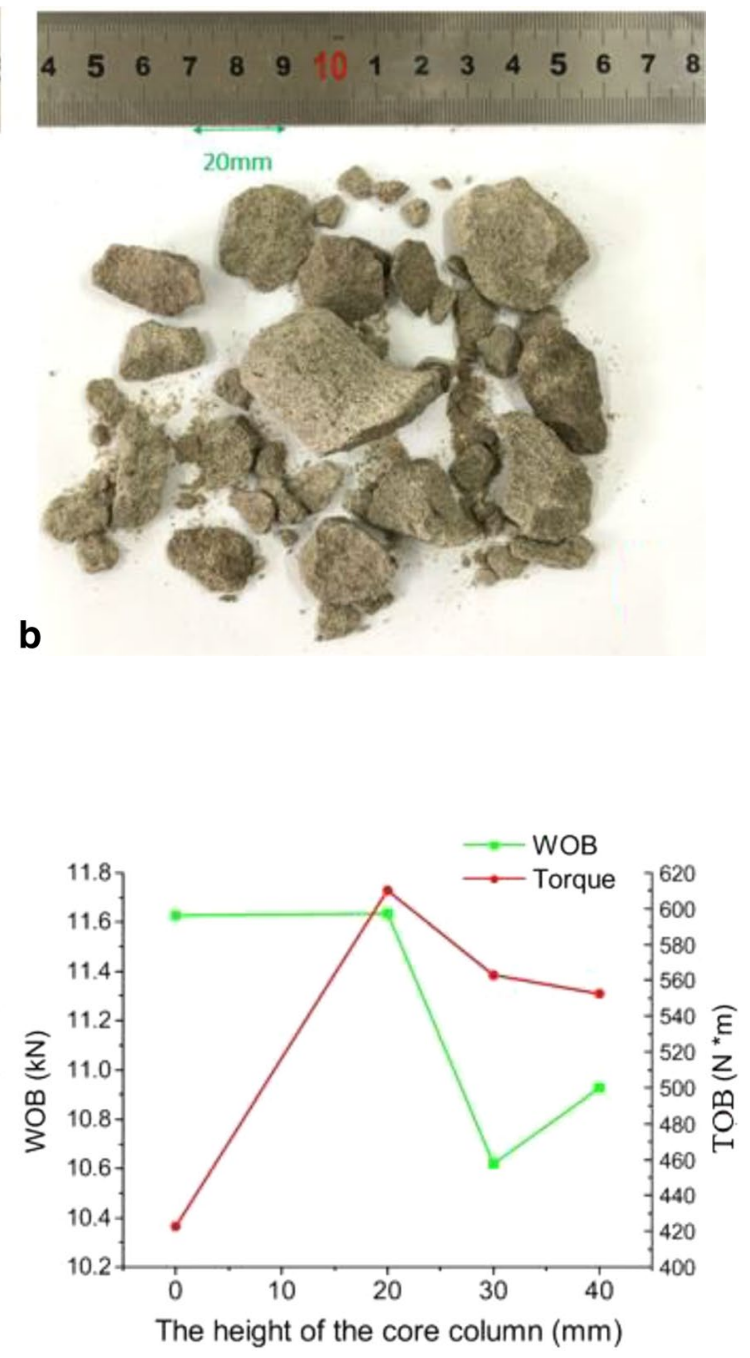

Fig. 19 Variation of WOB and TOB with diameter and height of the core column 


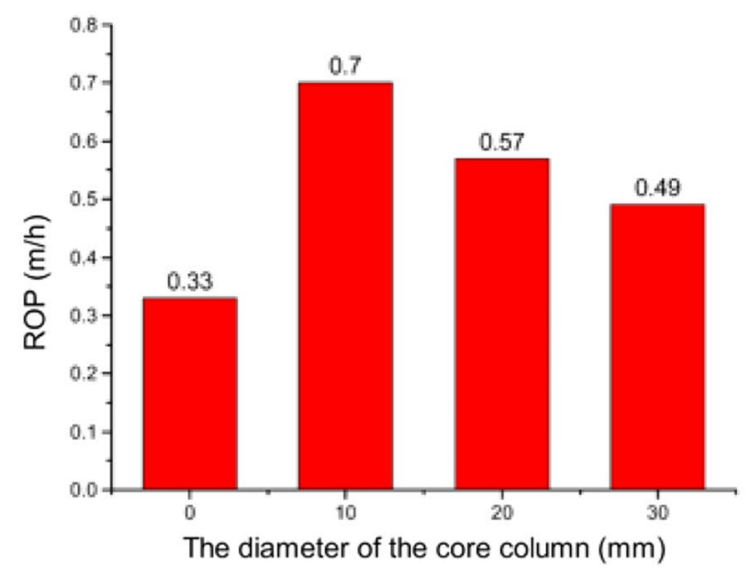

Fig. 20 Variation of ROP with diameter and height of the core column

diameter. Compared with the full-covering bit, ROP of the micro-coring bit increases from 49 to $112 \%$, depending on different diameter. On the other hand, in the experiment of changing the height of core column, TOB of the micro-coring bit substantially decreases with the increase of height. Compare with the full-covering bit, ROP of the micro-coring bit increases from 49 to $67 \%$, depending on different height of the column.

It can be concluded from the indoor experiment that the micro-coring bit, compared with the conventional PDC bit, can increase ROP significantly. The reason lies in two aspects. On the one hand, cutting ability and cutting efficiency of the cutters in different position are quite different. Cutters of high efficiency have to wait those of low efficiency to drill further, just as the barrel principle, ROP of the bit depends on ROP of the weakest cutting element. For the cutters in the central area of the conventional PDC bit, the rock-breaking mode is extrusion or impact, but not scraping and cutting as the cutters in outer area, so that the rockbreaking efficiency is quite low, thus greatly reducing the ROP of the bit. On the other hand, the existing of central cutters may cause a side effect called pressure-absorbing, i.e., the central cutters with low efficiency always function as a pressure-bearing part where most of the WOB is consumed, while cutters in outer area cannot get enough pressure to penetrate in the rock, the WOB distribution is quite unreasonable. For the micro-coring bit, since there are no cutters in the central area but a rock-fracturing structure in the central groove instead, pressure-absorbing will not occur in this area, most of the WOB is applied on cutters in outer area (i.e., the cutters of high efficiency), cutters of high efficiency get enough pressure to penetrate in the rock. When the core column grows and contacts the rock-fracturing structure (a PDC cutter, a conical tooth or a slanted plane, etc.), volumetric fracturing will occur. Since the specific work of breaking the core column is much lower than breaking a flat rock, and

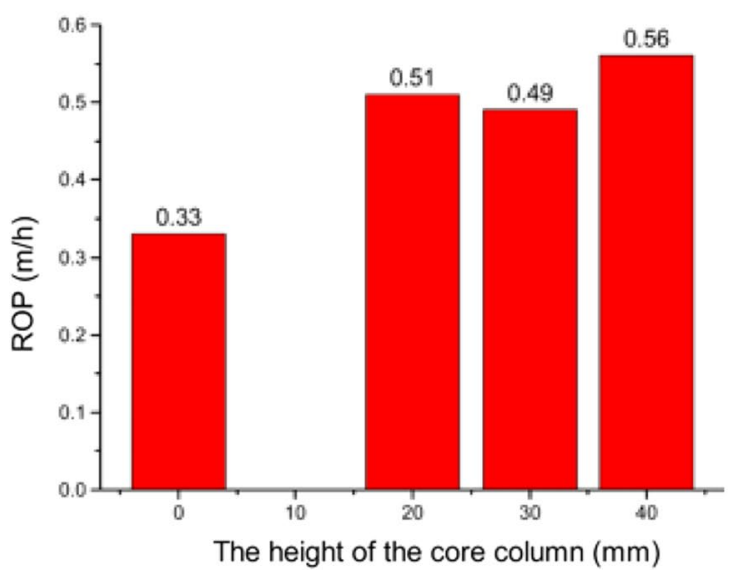

the interaction time is quite short, the pressure-absorbing effect can be avoided or greatly weaken. As a result, ROP of the bit is significantly increased.

According to the variations of WOB and TOB with the diameter and height of the core column, as shown in Fig. 19, the influence of the central groove diameter (corresponding to the diameter of the core column) on ROP is more significant than the depth of the column (corresponding to the height of the core column). When the diameter of the central groove is $10 \mathrm{~mm}$ and the height is $30 \mathrm{~mm}$, the ROP reaches its maximum $0.7 \mathrm{~m} / \mathrm{h}$, obviously higher than the other groups. The reason is that the bit axis cannot always be strictly aligned with the column axis, causing the diameter of the column to be smaller than $10 \mathrm{~mm}$. Meanwhile, lateral vibration always exists in the drilling process, if the diameter of the core column is small enough, the column will be directly fractured by the lateral vibration of the drill bit, but not grow until being broken by the rock-fracturing structure, so the pressure-absorbing effect will not appear at all. If the column is never formed in the bottom hole but always be broken by lateral vibration, the micro-coring bit will get the highest rock-breaking efficiency. So the experiment results indicate that the diameter being $10 \mathrm{~mm}$ is the special case where the core column is never formed and that the axiality between the bit and bottom hole will directly affect the optimal diameter of the central groove in the micro-coring PDC drill.

\section{Conclusion}

(1) The unit breaking experiment shows that:

(A) The specific work of breaking the core column is much lower than breaking a flat rock;

(B) Each of the three kinds of rocks (sandstone, limestone, and granite) has, respectively, got the size with highest 
rock-breaking efficiency under the two types of breaking method (static-pressure and fracture breaking);

(C) The rock-breaking efficiency of fracture breaking is higher than that of the static-pressure breaking;

(D) Fracture breaking can achieve volumetric breaking in all the three kinds of rocks, indicating that the microcoring bit is applicable in soft, medium and hard formation.

(2) The indoor experiment on the micro-coring bit show that the micro-coring PDC bit can increase the ROP by $49 \%$ to $112 \%$ with respect to the common PDC bit. Compared with the height of the central groove, the diameter affects much more on ROP of the micro-coring bit.

(3) The indoor experiment reveals the rock-breaking mechanism of the micro-coring PDC bit. Pressure-absorbing will not occur in the central area of the bit, cutters of high efficiency get enough pressure to penetrate in the rock, so that ROP of the bit is significantly increased. Further, the column being never formed in the bottom hole is a special case that the micro-coring bit gets the highest rock-breaking efficiency.

Funding This project is supported by National Natural Science Foundation of China, [grant number: 51504209].

\section{Declarations}

Conflict of interest We declare that we have no financial and personal relationships with other people or organizations that can inappropriately influence our work, there is no professional or other personal interest of any nature or kind in any product, service and/or company that could be construed as influencing the position presented in, or the review of, the manuscript entitled.

Open Access This article is licensed under a Creative Commons Attribution 4.0 International License, which permits use, sharing, adaptation, distribution and reproduction in any medium or format, as long as you give appropriate credit to the original author(s) and the source, provide a link to the Creative Commons licence, and indicate if changes were made. The images or other third party material in this article are included in the article's Creative Commons licence, unless indicated otherwise in a credit line to the material. If material is not included in the article's Creative Commons licence and your intended use is not permitted by statutory regulation or exceeds the permitted use, you will need to obtain permission directly from the copyright holder. To view a copy of this licence, visit http://creativecommons. org/licenses/by/4.0/.

\section{References}

Chengdu Best Diamond Bit Co Ltd. (2013) Micro-coring bit [P] CN203 114180U, 2013-0807

Deschamps B., DEsmette S., Delwiche R., et al. (2008) Drilling to the Extreme:the Micro-Coring Bit [J] Concept.IADC/SPE Asia Pacific Drilling Technology Conference and Exhibition.25-27 August

Huichao Yu, Jing Y, Ruidong T et al (2016) Application of micro-core bit in Nanpu 3-82 well. West-China Exploration Eng 12:66-68

Jing Liu, Han Gao, Bi Cheng Guang et al (2014) Test and evaluation of micro coring PDC bit. Drill Production Technol 37(3):24-35

Meng Z, Rui C, Shengwu W et al (2016) Application of micro core bit in Jidong Oilfield. Liaoning Chem Ind 45(1):124-126

Smith International,INC.Drill bits with core feature for directional drilling applications and methods of use thereof [P]. 30 June 2016 WO 2016/105906A1 PTC

Tian Yu W (2017) Principle and field application of micro core bit. Standard Quality China's Petroleum Chem Ind 23(3):78-80

Ulterra Drilling Technologies,L.P.Drill Bit [P],Aug.20,2015,US 2015/0233186 A1

Xin H (2015) Research on improving the speed of mechanical drilling by micro drill bit. Liaoning Chem Ind 44(10):1213-1214

Yuchun K, Jinwu L, Li W et al (2017) Research and application of suction microcoring PDC bit. J Petroleum 38(9):1073-1081

Publisher's Note Springer Nature remains neutral with regard to jurisdictional claims in published maps and institutional affiliations. 